\title{
The Dynamic Process of Racial Steering in U.S. Housing Markets*
}

\author{
Matthew Hall \\ Cornell University \\ Jeffrey M. Timberlake \\ University of Cincinnati \\ Elaina Johns-Wolfe \\ University of Cincinnati \\ Alex Currit \\ Cornell University
}

March 27, 2020

Word Count: 10,306

Keywords: discrimination, steering, segregation, racial inequality, housing, neighborhoods

* Direct correspondence to Matt Hall, Cornell University Department of Policy and Management, Martha Van Rensselaer Hall, Ithaca, NY 14853. E-mail: mhall@cornell.edu. We are grateful to Erin York Cornwell, John Iceland, Peter Rich, and Laura Tach for comments on previous drafts; and to the National Science Foundation (Grant No. 1226858), the Cornell Population Center at Cornell University, and the Charles Phelps Taft Research Center at the University of Cincinnati for funding for this study. 


\title{
The Dynamic Process of Racial Steering in U.S. Housing Markets
}

\begin{abstract}
Housing discrimination has long been thought to contribute to the persistence of racial segregation, yet evidence indicates that explicit forms of housing discrimination have waned. We argue that past work has not fully considered the role of racial steering in maintaining segregation. To explore patterns of steering, we use the 2012 Housing Discrimination Study along with Census data on the neighborhood racial and socioeconomic composition of housing units shown to testers. We leverage the experimental design of the audits to examine how neighborhoods of homes shown to auditors change dynamically throughout the search process and to assess the conditions under which steering is most likely. As with past research, we find no evidence of steering in Asian-White or Hispanic-White audits. However, we find consistent evidence that Black testers are steered away from White neighborhoods and toward Blacker ones, particularly for female homeseekers and those with children. We also find that steering occurs relatively early in the search process and is heightened when searches begin in racially-homogenous neighborhoods. These findings support arguments that the steering of Black homeseekers serves as a modest but stubborn mechanism by which segregation is maintained, and highlight the intersectionality of race and gender in determining outcomes.
\end{abstract}


After rising sharply in the first half of the $20^{\text {th }}$ century and reaching peak levels in about 1970, residential segregation between African Americans and other racial ${ }^{1}$ groups has declined steadily over the past five decades (Timberlake and Iceland 2007; Logan and Stults 2011; Vigdor and Glaeser 2012). Scholars have offered several explanations for this trend, including the growing diversity of the U.S. population, convergence on racial gaps in predictors of residential mobility and housing access, long-run declines in intolerance for having different-race neighbors, and the stronger implementation of institutional and governmental policies that limit - or increase the costs of - racial discrimination in housing markets. Whatever the causes, their effects have prompted some scholars to claim that we are at the "end of the segregated century" (Vigdor and Glaeser 2012).

On the other hand, American residential life remains defined by the spatial separation of groups, with the average White person still living in a neighborhood that is overwhelmingly White (Iceland and Sharp 2013). Levels of segregation between Blacks and Whites remain high in absolute terms, and segregation between Whites and Hispanics or Asians has stagnated or even increased slightly over time (Timberlake and Iceland 2007; Logan and Stults 2011). In attempting to account for the persistence of residential segregation, scholars have focused on what Krysan and Crowder (2017) refer to as the "Big Three" theoretical explanations: socioeconomic differences between groups, group

\footnotetext{
${ }^{1}$ We use "race" to denote categories of people defined by observable phenotypical characteristics, such as skin tone and facial features. In contrast, "ethnicity" is often used to define groups on the basis of national or cultural origins, which frequently are nested within "racial" categories. Although both the categorization of people into "races" and the social meanings of those categories are socially constructed, for scholars of discrimination this is not a concern but rather the point - all theories of discrimination involve actors' making choices about the treatment of others based on the social meanings attached to assumed group membership. As a result, in this paper we do not distinguish between race and ethnicity because ethnicity is not directly observable in the way that race is. As such, we refer to Whites, Blacks, Asians, and Hispanics as "racial groups" because it is likely that preferential or discriminatory behavior on the part of real estate agents would be triggered by the pairing of agents' racial identification of testers with beliefs about the traits of members of those groups.
} 
preferences for residing in largely same-race neighborhoods, and racial discrimination in housing markets.

Prior to the passage of the Fair Housing Act in 1968, many forms of discrimination were not only overt, but encoded in the policies and practices of institutions such as the Federal Housing Administration (Rothstein 2018; Taylor 2019) and the National Association of Real Estate Boards² (Gotham 2002; Massey and Fischer 2004). As a result, analyses of audit data from the 1970s and 1980s showed high levels of blatant, easily observable discrimination against minority homeseekers (Wienk et al. 1979; Hakken 1979; Yinger 1995). However, likely due to the cumulative effects of the Fair Housing Act ${ }^{3}$ and other social changes following the Civil Rights era, the incidence of housing discrimination has declined sharply over time, at least as observed in the 1989, 2000, and 2012 Housing Discrimination Studies carried out by the U.S. Department of Housing and Urban Development (HUD) (e.g., Ross and Turner 2005; Turner et al. 2013; Pitingolo and Ross 2015). The available evidence thus poses a dilemma for proponents of the discrimination hypothesis for persistent segregation: how could discrimination be the culprit when a longrunning set of large-scale, harmonized audit studies show steep declines in its incidence?

We argue that one possible explanation may be that scholars have not properly accounted for the role of racial steering in residential housing markets. Put simply, steering occurs when homeseekers are systematically shown housing units in neighborhoods that are disproportionately composed of same-race residents (Bruce 1977; Galster and Godfrey 2005;

\footnotetext{
${ }^{2}$ Until 1950 the National Association of Real Estate Boards stated in its code of ethics that "a realtor should never be instrumental in introducing into a neighborhood... members of any race or nationality... whose presence will clearly be detrimental to property values in that neighborhood" (Massey \& Denton 1993, p. 37).

${ }^{3}$ Because the 1968 Fair Housing Act was relatively weak on enforcement provisions and penalties for discriminators, it is likely that stronger policy effects would have issued from the amended Act in 1988 (Massey and Denton 1993; Schill and Friedman 1999).
} 
Oh and Yinger 2015). If potential movers tend to be shown housing in neighborhoods composed largely of members of their own racial group, then segregation would persist even with salutary changes in other causes of segregation, including other forms of discrimination. The theoretical and policy significance of steering is underscored by the fact that it does not require anti-minority sentiments or practices to operate. Indeed, steering may occur when agents believe they are offering good service to their customers, White and minority alike. Hence, increasing or persistent steering over time is not incompatible with evidence that more explicit forms of discrimination are in decline.

The general concept of steering is well-known and scholars have devoted some attention to it. However, the present study is the first to conceive of and measure steering as it would unfold dynamically throughout the home search process. Past research has largely averaged the racial composition of neighborhoods in which homeseekers viewed or were told about. As we show below, this technique may result in both false positives and negatives, and provides no evidence on who is being steered, the conditions under which steering is more or less likely, and when in the search process steering occurs. In contrast, in this paper we analyze the composition of neighborhoods according to the sequence of housing units shown or recommended to White and minority homeseekers. This allows us to assess when steering tends to occur, and which group of homeseekers, if any, are more likely to learn about homes in neighborhoods with differing racial compositions or socioeconomic status characteristics as housing searches progress.

To carry out our analysis, we rely on audits of the sales market ${ }^{4}$ from the 2012 Housing Discrimination Study (HDS) in which pairs of "testers" — one White and one either

\footnotetext{
${ }^{4}$ We focus solely on the sales market because rental housing agents generally have limited control over units that they do not manage or own; thus, steering in the rental market is less likely to occur. Indeed, in
} 
Black, Hispanic, or Asian-were matched on certain observable traits such as sex and age, and then given matched profiles on such unobservable attributes as education, income, assets, marital status, and presence of children. Each member of the pair visited advertised housing units and recorded their experiences with housing agents, who showed them the initial unit plus others that were either shown or recommended. Because agents were free to show testers additional units in different neighborhoods, we are able to assess the extent to which the housing searches carried out by testers took them from a common origin point to differing neighborhood destinations as the search process unfolded.

We argue that this paper contributes to the literatures on both housing discrimination and residential segregation. Regarding the former, our approach is the first to measure steering dynamically, by tracking the sequence of housing units and neighborhood compositions throughout the search process. We recognize that the evidence we present would not necessarily conform to legal definitions of unlawful steering (see Bruce [1977] and U.S. DOJ [2020] for reviews of steering cases); however, our analyses assess the extent to which there is prima facie evidence for significant steering in the U.S. sales market. In terms of the research on residential segregation, we provide novel evidence on a theoretically proposed but understudied mechanism by which segregation may be maintained. Here too, we stress that our results do not provide clear evidence of the causal effect of steering on segregation. Rather, we argue that our analyses investigate the plausibility of such a link. In other words, if steering does not happen systematically, then it is hard to see how it could perpetuate segregation. If we do find evidence of steering, then

supplemental work, using the techniques used in this analysis and the 2012 HDS rental audits, we have concluded that there is no evidence of significant steering in the rental market. 
it is at least plausible that steering may play a role in continuing segregation, although the precise effect size would remain unknown.

\section{Theoretical Background}

\section{$\underline{\text { Definitions of Steering }}$}

Although the Fair Housing Act does not identify steering as a major category of "Discriminatory Housing Practices," $\$ 100.70$ lists several "unlawful steering practices" relevant to protected classes based on "race, color, religion, sex, handicap, familial status, or national origin" (HUD 2019a). These practices include "[d]iscouraging any person from inspecting, purchasing or renting a dwelling because of [membership in a protected class], or because of the [protected class] of persons in a community, neighborhood or development," (c1), "[a]ssigning any person to a particular section of a community, neighborhood or development, or to a particular floor of a building, because of [membership in a protected class]," (c4), "[e]mploying codes or other devices to segregate or reject applicants, purchasers or renters, refusing to take or to show listings of dwellings in certain areas because of [membership in a protected class]," or "refusing to deal with certain brokers or agents because they or one or more of their clients are of a particular [membership in a protected class]" (d2).

Although the wording of the Fair Housing Act focuses on the denial of opportunities due to membership in a protected class, Bruce (1977) argues that steering occurs "when a potential customer is either encouraged or discouraged from purchasing housing in a particular area or community because of the agent's actions" (pp. 758-759, emphasis 
added). ${ }^{5}$ Other scholarly definitions include those of Galster and Godfrey (2005), who describe racial steering" as "behaviors by real estate agents that differentially direct clients toward particular neighborhoods and away from others on the basis of race or ethnicity" (p. 251), and Oh and Yinger (2015), who suggest that "steering occurs when the characteristics of the neighborhoods in which a homeseeker is shown houses depend on the homeseeker's race or ethnicity" (p. 29).

We follow the examples of past research in conceiving of steering as a two-sided coin in which agents take affirmative steps either to encourage homeseekers to search or settle in certain neighborhoods, or to discourage homeseekers from searching or settling in certain neighborhoods. Empirically, even if we do not directly observe encouragement or discouragement - such as verbal statements or non-verbal cues from agents - we may assume that steering occurs if White and minority homeseekers are, in expectation, shown homes in increasingly same-race neighborhoods as housing searches unfold. Theoretical Motivations for Steering

Scholars have suggested three general motivations for steering by housing agents. One model asserts that unfavorable treatment occurs due to a "taste for discrimination"

\footnotetext{
${ }^{5}$ In a document on hud.gov titled "Examples of Housing Discrimination," the illustration of steering reads as follows: "John, who is an Asian man, meets with a real estate broker to discuss purchasing a house for his family. When John names the neighborhood that he is interested in, the broker asks John if he is sure that his family will feel comfortable there. The broker tells John that she has a wonderful listing in another neighborhood where there are more "people like them." When the broker takes John to see the house, John notices that the residents of the neighborhood appear to be mostly Asian. John files a complaint with HUD because steering someone to a certain neighborhood because of his race is a form of race discrimination" (HUD 2019b).

${ }^{6}$ Galster and Godfrey (2005) distinguish between "information steering," which refers to a differing number and spatial pattern of areas shown to White and minority customers, "segregation steering," which refers to minorities' being shown homes in neighborhoods with higher percentages of minority residents than the homes shown to White customers, and "class steering," which refers to minorities' being shown homes in neighborhoods with lower socioeconomic status than the homes shown to White customers. We use the term "racial steering" to indicate each of the latter two forms - segregation and class steering.
} 
(Becker 1971). Although this motivation has typically been used to explain the denial of service to minority customers - such as refusing to show units at all - the theory could extend to steering. For example, agents could provide information to minority homeseekers on different housing units or in different neighborhoods based on personal beliefs about where minorities "should" (or "should not") live. While this motivation is difficult to detect in the absence of other information on poor treatment of minority clients, we argue that any taste for discrimination should be more common among White housing agents than non-White ones, and thus support for this mechanism would come from observing clear patterns of steering by White agents, but not non-White ones.

The two other general explanations for steering relate to agents' beliefs about how to maximize short- and medium-term returns on time spent with customers. First, agents may worry about the impact of introducing minority residents into White neighborhoods on the desirability of neighboring units or homes in future transactions. In practice this would mean that agents would avoid showing minority homeseekers in predominantly White neighborhoods to avoid incurring the dissatisfaction of White residents, who may comprise some portion of the agent's client base. On the other hand, placing minority homebuyers in White neighborhoods might accelerate the process of racial turnover, leading to more vacant homes and greater chances for sales and commissions. Hence, without knowledge of the context of specific neighborhoods it would be difficult to develop strong assumptions about this motivation for real estate agents' steering minority clients.

Furthermore, it is difficult to imagine how this theoretical motivation would lead agents not to show White clients homes in minority neighborhoods - that is, to steer White clients to White neighborhoods - for two reasons. First, survey research shows much higher levels of tolerance among minorities for having White neighbors, and while it is unlikely 
that the typical housing agent has examined this research, it is plausible that professionals in the housing market would have at least a folk understanding of differential attitudes toward other-race neighbors among White and minority residents. Hence, it is unlikely that the same kinds of "customer prejudice" concerns would occur when White homeseekers are shown homes in minority neighborhoods. Second, it is conceivable that introducing White households into predominantly minority neighborhoods would serve to signal the desirability of such neighborhoods for future customers, White and minority alike, which would tend to increase the demand and therefore housing prices in those neighborhoods, relative to their remaining predominantly minority in composition.

A second type of rational calculation on the part of agents would occur if agents engage in a version of "statistical discrimination," by using the race of the homeseeker as a proxy for unobservable characteristics of customers that may affect the likelihood of completing a sale (Phelps 1972). For instance, agents may believe that it is a "waste of time" to show White customers homes in minority or poorer neighborhoods because they would not want to settle in such neighborhoods. Similarly, agents may avoid showing minority customers homes in White or more well-to-do neighborhoods because they may assume that such clients would not want or could not afford to settle there. Finally, agents may show customers units in same-race neighborhoods under the assumption that homeseekers would feel more comfortable or otherwise approve of residence in a neighborhood with many same-race neighbors. It is in this sense that steering is consistent with the possibility that agents believe they are providing good service to their clients.

As we show in the following section, past quantitative research has provided some clues as to what the motivations are, although it has been challenging to disentangle the effects of these three possible explanations - taste for discrimination, customer prejudice, 
and statistical discrimination. There is some recent evidence from qualitative research that the last of these may occur with some frequency (see Besbris and Faber 2017; Korver-Glenn 2018). Nevertheless, for the purposes of this study we focus less on the motivations and more on the measurement and prima facie evidence of steering, as we argue that our approach surmounts some of the limitations of past steering research.

$\underline{\text { Prior Research on Steering-Measurement and Evidence }}$

Past studies of steering using paired-tester audits have overwhelmingly relied on one of three basic strategies for estimating its incidence. First, analysts have calculated the percentage of units shown to White and minority testers in neighborhoods with particular racial or economic compositions. Steering is assumed to happen when the distributions of neighborhood racial or economic compositions vary between White and minority testers. Using this technique, Pearce (1979) showed evidence that Black couples were shown homes in neighborhoods with lower incomes, housing prices, and percentages of White residents than were comparable White couples. A second technique, adopted by Ondrich, Ross, and Yinger (2001, 2003), estimates the probability that specific homes are shown to both pairs of testers in Black-White audits. The authors find that the probability of matched homes increases with respect to distance from the agent's home office, suggesting that customer prejudice is at play.

Most commonly, analysts have averaged the neighborhood characteristics (such as percent Black or percent poor) of the homes shown or recommended in an audit, and compare these averages between White and minority testers, typically with some tolerance threshold (such as an average difference of $5 \%$ or $10 \%$ in terms of White or poor residents). Each audit then receives a trichotomous steering score, where, for example, a score of -1 would be given to an audit in which the minority tester was favored (i.e., the minority 
tester was recommended or shown homes in neighborhoods with a higher average percentage of White residents or lower average poverty rate than the neighborhoods in which the White tester was recommended or shown homes), a score of 0 would be given to an audit in which the two testers were treated equally, and a score of 1 would be given to an audit in which the White tester was shown homes in more White, less poor neighborhoods than the neighborhoods in which minority testers were shown homes, on average. Finally, the percentage of minority-advantaged audits is subtracted from the percentage of Whiteadvantaged audits (referred to by Galster and Godfrey 2005 as "promoting integration" or "promoting segregation," respectively) to arrive at a "net" incidence of steering.?

Using this technique, Galster (1990) calculated a steering incidence of about $40 \%$ to $60 \%$ in audit studies of Cincinnati and Memphis during the mid-1980s, with the range depending on city, geographic scale (e.g., blocks versus tracts), and the measure used (e.g., comments made by agents versus neighborhood racial composition). In an analysis of data from the 1989 HDS, Turner, Edwards, and Mikelsons (1991) calculated steering incidences of about $10 \%$ when the measure was neighborhood percent White, and $17 \%$ to $18 \%$ when the measure was one of two "composite indexes," which combined neighborhood racial composition, income, and home values. Galster and Godfrey (2005) analyzed 2000 HDS data and found very low net steering incidences on the basis of percent White in the census

\footnotetext{
${ }^{7}$ The use of "net" measures of discrimination is justified in the literature as removing random variation in the poor treatment of minority testers. This technique assumes that the only way in which minorities would be treated better than Whites is due to randomness, and that this random incidence of better treatment is equal to the percentage of audits in which White customers are treated better simply due to chance (Wienk et al. 1977; Galster 1990). So, for example, if the percentage of audits in which Whites were treated better were $50 \%$ and the percentage in which minorities were treated better were $10 \%$ (with the remaining $50 \%$ reflecting equal treatment), the idea is that this latter percentage should be removed from the former to arrive at a $40 \%$ "net discrimination" score. However, it is not necessary to accept the argument that audits in which minorities are treated better is "random" to adopt this strategy, since the "net discrimination" score could simply be interpreted as the extent to which White testers are treated better over and above the extent to which minorities are treated better.
} 
tract of recommended or shown homes (ranging from 1\% to 4\%) and considerably higher net steering incidences on the basis of editorial comments among agents, in which $12 \%$ to $14 \%$ of audits promoted segregation versus promoting integration. These authors found virtually no difference between White and Hispanic testers on measures of steering.

Ross and Turner (2005) also observed low net steering incidences for Black testers using sales market data from the 2000 HDS. Their data show that in Black-White audits, Black testers were steered toward Black neighborhoods about $4 \%$ to $5 \%$ more frequently than they were steered to White neighborhoods. These incidence rates are somewhat consistent with those calculated by Galster and Godfrey (2005); however, Ross and Turner (2005) also show that the incidence of adverse steering for Blacks increased during the 1990s. That is, in 1989 the net steering measures were $-5.8 \%$ and $-2.4 \%$ for recommended and shown homes, respectively, indicating that if anything, Black testers in 1989 were steered toward White neighborhoods. As with Galster and Godfrey (2005), Ross and Turner (2005) found no significant evidence of steering in Hispanic-White audits in HDS 2000.

More recent evidence of steering comes from the addition of HDS 2012 to its 1989 and 2000 siblings. As found in Ross and Turner (2005), Oh and Yinger (2015) find increases in the net incidence of racial steering from 2000 to 2012. In terms of homes being recommended in Whiter tracts, the Black-White net steering incidence was 8\%, up from $4 \%$ in 2000. In terms of homes being inspected in Whiter tracts, this incidence was 5\%, up (marginally) from $4 \%$ in 2000. These authors find no significant steering in Hispanic-White audits in terms of recommended homes, but they do report significant steering in 2000, slightly at odds with the findings of Ross and Turner (2005). 


\section{Limitations of Prior Research on Steering}

Based on prior quantitative analyses of steering, we conclude that the evidence is mixed, both in terms of the severity of steering and the extent to which it has changed over time. While this research has contributed much to our understanding of steering, we argue that the reliance in the extant research on averaging differences between testers suffers from three fundamental limitations. Most importantly, by averaging the neighborhood characteristics of homes recommended or shown, it is plausible that a number of false positives and negatives are identified, leading to uncertainty in the incidence of steering. Figure 1 below displays the problem in graphical form, where each panel represents a hypothetical audit with a White and a minority tester. Example 1 represents the paradigmatic case of steering, in which both testers initially see a home in a neighborhood that is $50 \%$ White. As the audit progresses across a sequence of 9 additional homes, the percentage White increases for the White tester and decreases for the minority tester. In this case, we would observe both significant steering and a significant difference in the percent White in the neighborhoods shown to each tester.

In example 2, the two testers begin their search in different neighborhoods, which occurred in a nontrivial set of audits in the HDS (see footnote 9). Here there is evidence of significant steering, as the minority tester is recommended or shown homes in increasingly non-White neighborhoods and the White tester is shown homes in increasingly White neighborhoods. However, simply averaging the racial compositions across the 10 neighborhoods would result in no significant difference in the average, leading to a false negative. In example 3, we argue that although the average percent White in neighborhoods shown to the White tester is higher than the average for the minority tester (largely on the basis of two outliers - neighborhood 4 for the White tester and neighborhood 6 for the 
minority tester), there is no obvious way in which the two testers were explicitly steered into different kinds of neighborhoods. This, we argue, would result in a false positive.

\section{[FIGURE 1 ABOUT HERE]}

A second limitation of past research is a clear understanding of who is being steered. That is, do White testers see increasingly White neighborhoods throughout the search, do minority testers see decreasingly White neighborhoods, or both? Furthermore, are particular subcategories of testers more or less likely to be steered? Are women more or less likely to be steered? Are those with children at a higher risk of steering? Similarly, prior research has been unable to assess the conditions under which steering is most likely. Is steering more common when the search involves a White housing agent? Does the degree of steering depend on the neighborhood racial composition or listing price of the initial home? Answers to these questions not only help us to understand the conditions under which steering is more likely, but also provide tentative support for theoretical arguments about the mechanisms through which steering may operate.

Finally, by not tracking the sequence of homes shown to testers, past research has not been able to assess when in the search process steering occurs. This limitation matters both empirically, by providing no information on the dynamics of steering, but also has direct implications for the potential harm done to steered individuals or families and the implications of steering for persistent residential segregation. If steering tends to occur very late in the search process, then homeseekers would have some exposure to neighborhoods that could result in integrating moves. On the other hand, if steering tends to occur immediately, then homeseekers would have much less information at their disposal regarding homes in diverse or majority other-race neighborhoods. 
In sum, our approach allows us to assess steering as a dynamic process, which reduces the risk of false positives and negatives, and enables an analysis of who is being steered and when in the search process it may occur. In the remainder of this paper we describe our novel approach, present results, and discuss their implications for future research and policy interventions meant to disrupt residual discrimination in housing markets.

\section{Data, Measures, and Methods}

$\underline{\text { Data }}$

To assess the incidence of steering in the housing market and to test related theoretical arguments, we draw on housing audit data from the 2012 Housing Discrimination Study (HDS). The Department of Housing and Urban Development (HUD) has been engaged in monitoring patterns of housing discrimination since 1977 when it first commissioned a largescale audit of racial discrimination in U.S. housing markets (Wienk et al. 1979). Since then, HUD has sponsored audit studies about once every decade (in 1989, 2000, and 2012), with some variation over time in the housing markets tested.

The strength of the HDS studies lies in the experimental nature of housing audits, whereby racially-dissimilar, but otherwise similar, testers independently respond to advertisements for housing and record their experiences during the housing search process. More specifically, two testers - one White and one nonwhite - are matched on sex and age group, and then assigned a common economic and demographic profile, including similar incomes, occupations, assets, and debts, along with a common marital status, number of children, and housing preferences. This design produces, in theory, estimates of discrimination during the initial housing search process that are not confounded by non-

racial characteristics of home-seekers that differ by race. While the audit methodology is 
not without its critics (Heckman and Siegelman 1993; Heckman 1998), it nevertheless provides a more powerful test of discrimination than studies relying on statistical adjustment of observational data (National Research Council 2004; Oh and Yinger 2015; Quillian 2006).

Advertised housing units were selected via a three-step sampling process: (1) randomly selecting a ZIP code that is weighted proportionately to the volume of sales listings in a metropolitan area; (2) randomly selecting ten recent housing advertisements within the sampled ZIP code from a database of continuously-harvested online listings (e.g., from a MLS or Zillow); and (3) identifying the first "eligible" unit from this set of ten advertisements, defined as units within the desired price range that are being sold on the regular market (e.g., not a foreclosure or short sale) and have not been previously audited. After inquiring about the availability of an advertised unit, each tester visited with a housing agent and documented their experiences along several dimensions, including detailed information on each unit shown or recommended to the tester (e.g., price, size), agent inquiries or comments about qualifications, unit condition and geographic location, and follow-up contact from the housing agent. For a detailed description of the sampling strategies, tester protocols, and data collection, see Turner et al. (2013).

For this study, we rely on the paired White-Black, White-Hispanic, and White-Asian tests in the sales markets of 28 metropolitan areas. We assembled our database at the housing-unit level, keeping track of when in the housing search a unit was recommended or shown, along with features of each unit and its geographic location. Overall, HDS testers were referred to an average of 5.9 homes in the sales market, with a minimum of 1 and a maximum of 39. Because the paired tests were conducted a median of 2 days from each other, it is possible that an advertised unit was no longer available by the time the second 
tester attempted to visit. Accordingly, we report results using two different analytic samples: (1) all audits in which both testers made contact with the agent (and saw units); and (2) the subset of the audits in sample (1) in which the testers not only made contact with the agent, but also saw the same first unit at the start of their search inquiry. ${ }^{8}$ The difference in these samples is nontrivial, with only about half of all audits starting at the same first unit. ${ }^{9}$

\section{$\underline{\text { Measures }}$}

To characterize the neighborhood attributes of analyzed housing units, we validated, corrected, and standardized the unit addresses using ZP4net and geocoded each unit using the ArcGIS 10.4 StreetMap locator, which uses Tele Atlas' 2012 street data to identify locations. The $26.9 \%$ of addresses that were not perfectly matched to a street location were further processed via Google Maps APIv3, and assigned final coordinates based on comparison of StreetMap to Google accuracy predictions. About $2.4 \%$ of addresses were deemed too inaccurate or otherwise not identifiable for use and were discarded from our analytic sample. With the geocodes, we spatially joined Census block group from the 2010 TIGER/Line files, which are used to characterize the neighborhoods' surrounding housing units on several dimensions, including racial composition, poverty, educational attainment, and home values. We measured these variables from the 2010-2014 American Community Survey summary tables for Census block groups. Given the imprecision of ACS block group estimates, as a sensitivity check we re-specified our models using Census tracts as the

\footnotetext{
${ }^{8}$ HUD did not retain indicators of whether a housing unit was the original advertised (sampled) unit. In order to match units within each audit, we calculated the spatial distance between the geocodes of every unit and assume that common advertised units are first-shown units within 100 meters of each other. Estimates based on plausible alternatives (e.g., 200 meters, same census block, same census block group) yield substantively identical findings.

${ }^{9}$ Specifically, 46\%, 47\%, and 49\% of Black-White, Hispanic-White, and Asian-White audits, respectively, involved testers seeing the same first unit.
} 
neighborhood unit. As shown in Appendix Table A1 for Black-White audits, we reach similar conclusions to those reported in this paper (tract-level results from other specifications also yield similar conclusions and are available on request).

While the experimental design of housing audits minimizes the confounding of nonracial characteristics that may distinguish testers, and our analytic design accounts for variation in audit and agent characteristics common to each tester, we incorporate a number of statistical controls for characteristics of testers (that vary within audits) that could impact treatment. Specifically, we include an indicator for whether a tester had a college education to account for possible differences in tester presentation or training. Similarly, we include an indicator for testers with prior (i.e., pre-HDS) experience conducting audits or correspondence studies. In addition, we include time (a.m./p.m.) and day dummies for the visit associated with each unit. Similarly, we control for whether a tester was first to visit to see the advertised unit. Descriptive statistics on these variables, by tester race, are shown in Appendix Table A2.

To test for heterogeneity in steering dynamics, we explore several features of audits and testers that may alter the potential for steering. In particular, we test whether minority housing agents are less likely to engage in steering behavior than are White agents and also consider the roles of tester sex and parental status as potential sources of differentiation. Similarly, we test whether steering processes are conditioned by the price of the advertised housing unit (relative to other homes in the county) and the racial composition of the neighborhood where the first unit is located.

Analytic Approach

Our empirical strategy seeks to model the temporal dynamics of the home search process and how characteristics of neighborhoods change as the number of units shown or 
recommended by housing agents increases. More formally, we estimate the following basic model:

$$
y_{i t j}=\gamma \mathbf{S}_{i t j}+\delta \text { race }_{t}+\tau\left(\mathbf{S}_{i t j} * \operatorname{race}_{t}\right)+\beta \mathbf{X}_{i t j}+\alpha_{j}+\epsilon_{i t j}
$$

where $y_{i t j}$ is a neighborhood characteristic associated with unit $i$, for tester $t$, in audit $j$; $\mathbf{S}_{i t j}$ is a vector expressing the search sequence of unit $i$ as a cubic polynomial ${ }^{10} ;$ race $_{t j}$ is a dummy indicating the race of tester $t ; \mathbf{X}_{i t j}$ is a vector of tester- or unit-specific controls; and $\alpha_{j}$ are audit fixed effects. The latter term accounts for all characteristics of unitsobserved or not - that are constant across testers (e.g., season of the visit, size of the agent's firm, metropolitan location). Our primary interest is in $\gamma$, which indicates the extent to which neighborhood features of housing units evolve throughout the home search, and $\tau$, which allows these curves to vary by tester race. Standard errors are clustered at the audit level, which takes into consideration the potential correlation of neighborhood outcomes between housing units within each audit.

\section{Results}

As discussed above, the extent of racial steering has conventionally been assessed by averaging neighborhood features across all housing units a tester was shown or recommended. We replicate this approach using our analytic sample of all audits and report results in Table 1. For Black-White audits, we see that homes shown to white testers tended to be located in slightly Whiter neighborhoods (64.6\%) than those shown to Black testers (62.0\%), a difference that is statistically significant. Likewise, Black testers were shown homes in slightly - and significantly_Blacker neighborhoods (11.2\%) than White testers

\footnotetext{
${ }^{10}$ Information criteria statistics (AIC and BIC) confirm that the cubic expression is the best-fitting model. We also considered models with search sequence in categorical time (i.e., dummies for each sequence number), and the substantive interpretation of the estimates is consistent with those presented here.
} 
(9.7\%). Hispanic and Asian neighborhood shares were not meaningfully different for White and Black testers. Similarly, comparing mean differences suggests no differences in neighborhood socioeconomic composition - poverty, education, or housing values - between the two groups of testers.

\section{[TABLE 1 ABOUT HERE]}

The second block of columns in Table 1 reports neighborhood outcomes for HispanicWhite audits, and shows small and statistically non-significant differences in the averages. Notably, the homes shown to White and Hispanic testers are located in neighborhoods with statistically similar White and Hispanic shares, although the small and non-significant differences work in expected directions. The same is largely true for audits involving White and Asian testers, with average neighborhood differences being very small. Most importantly, Asian testers appear to be shown homes in neighborhoods with similar White and Asian shares as their White counterparts.

Using the mean differences approach employed in most prior research on steering reveals relatively little evidence of steering, other than the modest differences in neighborhood racial composition between White and Black auditors. However, as we argued above, this approach may run the risk of generating an unknown number of false positives and negatives. Moreover, it yields no information on who is being steered, nor the timing of that steering in the home search process. To address these questions directly, we report estimates from models defined by equation (1) that recognize steering as a temporal dynamic, and compare neighborhood outcomes for testers within the same audit. We display estimates from these models in Tables 2, 3, and 4, for Black-White, Hispanic-White, and Asian-White audits, respectively. 
In each table, we report average marginal effects (AMEs) of the impact of additional homes being shown on neighborhood outcomes, for both White and minority testers. Recall that the sequence estimates are fit with a cubic polynomial, but we report AMEs to simplify interpretation and to calculate appropriate statistical tests for racial differences. The racial difference in these AMEs - i.e., the difference in the relationship between homes shown and neighborhood outcomes - is our primary indicator of race-based steering. For each table, we report results from our two analytic samples: the left set of models are for all audits; while the right set display results only for the roughly half of audits where the testers saw the same first housing unit.

Looking first at audits involving Black and White testers (Table 2), the models suggest that Black testers are progressively - and quickly-steered away from White neighborhoods and into Black neighborhoods. Specifically, for each additional unit shown to a Black tester, the percent White of the surrounding neighborhood decreases by about 1 percentage point, while percent Black increases by between 0.51 and 0.67 points, depending on the sample. The racial composition of units shown to corresponding White testers (i.e., those in the same audit), however, does not meaningfully change across units shown. The "p-val" column indicates that the difference in these estimates between White and Black testers is significant at the $1 \%$ level. The estimates also suggest that Black testers are steered slightly toward neighborhoods with greater Asian shares, although the point estimate is comparatively small, and is not significantly different from the estimate for White testers.

A visual representation of the underlying estimated curves (for all audits) is shown in Figure 2, which clarifies that the steering of Black testers comes early in the search process, and plateaus fairly quickly. At the fifth unit, for instance, the typical White tester was shown a home in a neighborhood that is about $65.6 \%$ White and $9.6 \%$ Black; while the 
same-audit Black tester was shown a home in a neighborhood that was $61.5 \%$ White and $12.2 \%$ Black.

\section{[TABLE 2 ABOUT HERE]}

\section{[FIGURE 2 ABOUT HERE]}

For the socioeconomic outcomes, there is no meaningful difference in neighborhood poverty or educational attainment between the homes shown to White and Black testers. However, analysis for the full sample of audits indicates that the steering of Black homeseekers does translate to Blacks' being shown home in neighborhoods with lower property values. Specifically, the estimates indicate that neighborhood median home values decline by about $\$ 5,500$ for each unit shown to a Black tester, but are undifferentiated for White testers. We do not, however, see any evidence of home value steering in the more stringent sample of testers who saw the same first unit.

\section{[TABLE 3 ABOUT HERE]}

\section{[TABLE 4 ABOUT HERE]}

Corresponding results for Hispanic-White audits are shown in Table 3 and estimates for Asian-White audits appear in Table 4. Broadly speaking and consistent with prior research, we see no systematic evidence of steering in terms of neighborhood racial composition or socioeconomic context against either Hispanics or Asians. For audits involving Asian and White testers, our estimates for the all-audit sample indicate a slight tendency for Asian testers to be shown homes in progressively more Asian neighborhoods, but the estimate is relatively small and not significantly different from the parallel estimate for White testers. In general, we find little evidence of neighborhood steering among Hispanic or Asian home seekers (at least in comparison to their White audit pairs). $\underline{\text { Conditions of Steering }}$ 
The preceding analysis points to signs that African American homeseekers are steered toward less White and more Black neighborhoods as the home search process unfolds. To better understand both the plausible motivations for steering and, more generally, the moderating influences of agent, tester, and unit characteristics, we test for heterogeneity in the steering estimates for Black-White audits across several dimensions, including characteristics of the agent, testers, and the advertised housing unit.

In Table 5, steering estimates for percent White and median home values are differentiated by the race of the housing agent, tester sex, and (assigned) tester parental status. In the first set of rows, we distinguish between audits involving a White housing agent and a minority housing agent. ${ }^{11}$ The estimates from the all-audit sample indicate that Black homeseekers are racially steered in similar ways - away from White neighborhoodsregardless of the race of the agent. The differences in neighborhood home values are somewhat more pronounced, with minority agents' steering White testers towards higherpriced neighborhoods and Black testers toward lower-priced neighborhoods; in contrast, White agents seem to steer Black testers only toward lower priced neighborhoods. The corresponding estimates for the more limited sample are generally consistent with this interpretation, although the racial difference from minority agents does not reach statistical significance. Our reading of these findings is that a simple "taste for discrimination" explanation is unlikely to describe the patterns of racial steering in contemporary housing markets; rather, White and minority agents appear to be acting in ways that are not markedly different from each other.

\section{[TABLE 5 ABOUT HERE]}

\footnotetext{
${ }^{11}$ For Black-White audits, about $20 \%$ of audits involved a primary agent that was nonwhite, with about one-third of those agents being black, half being Hispanic, and the remainder being another minority group.
} 
The middle set of models explores heterogeneity in steering by sex of the tester. ${ }^{12}$ The results clearly show that steering in terms of neighborhood race and neighborhood home values is concentrated among women testers, with both types of steering - and across both samples - not registering significantly for men. Specifically, the estimates suggest that for each additional unit shown to Black women, the neighborhood's White share declines by about 1.4 points and (in the broader sample) median home values by about $\$ 6,700$, whereas neighborhood characteristics for units shown to White women in those same audits remain largely unchanged. For men, there is a slight tendency for Black men to be directed to less White and less affluent neighborhoods, but the estimates are small and nonsignificant.

Lastly, the bottom portion of Table 5 tests for variation in steering dynamics by assigned parental status. ${ }^{13}$ The differences in the estimates are not prominent, with Black testers with and without children being significantly steered away from White neighborhoods. However, it is only for those with assigned children that the difference in steering is statistically significant (at the $5 \%$ level) between White and Black testers. A similar pattern, in the broader sample, is evident for neighborhood home values, with the point estimates for Black testers with and without children being approximately similar, but significant evidence of differential steering by tester race is only uncovered for testers who were assigned children.

In Table 6, we similarly assess variation in steering by features of the initial/advertised housing unit that both testers saw in common. In the upper portion of the table, we test whether steering is differentiated by the listed price of the advertised

\footnotetext{
12 The Black-White audits are approximately evenly split among male-paired (48.3\%) and female-paired $(51.7 \%)$ testers.

${ }^{13}$ In Black-White audits, about two-thirds (64.9\%) of tester pairs were assigned to have children, including $59.4 \%$ of male pairs and $70.0 \%$ of female pairs. Unfortunately, we do not have the statistical power to explore the joint interaction between gender and assigned parental status.
} 
housing unit, and find that it indeed is. Specifically, the estimates from both samples indicate that when an audit is initiated by a housing listing that is below the county median home value, there is no evidence of steering in terms of neighborhood racial composition, with neighborhood percent White staying relatively stable across the subsequent home showings for both White and Black testers. However, when the advertised unit is priced comparatively high (i.e., above the county median), evidence of the steering of Black homeseekers is clear. Specifically, when the audit begins with a higher-priced home, subsequent showings to Black testers are in neighborhoods that are progressively less White, whereas there is no change in the neighborhood racial composition of the homes shown to White testers. This process of steering away from higher-priced homes is also apparent in neighborhood home values, for the full sample, with Black testers being shown homes in increasingly lower-priced neighborhoods.

\section{[TABLE 4 ABOUT HERE]}

In the middle and bottom panels of Table 6 , we explore how these patterns of steering are conditioned by the racial composition of the neighborhood where the initial home is located. ${ }^{14}$ The estimates reveal several patterns. When the search begins in neighborhoods with relatively low White shares (less than 50\% White), both White and Black testers are steered toward Whiter neighborhoods, but the degree of steering is noticeably -and significantly - higher for White testers. We do not see such a pattern in moderately $(50 \%$ $75 \%$ ) White neighborhoods. However, in mostly-White neighborhoods (75\%-100\% White),

\footnotetext{
${ }^{14}$ In supplemental work, we explored a variety of alternative neighborhood racial composition cutpoints, including ones based on distributional tertiles, evenly-split thirds, and lower/higher thresholds for being considered low or high \% white/black. Results are substantively consistent across all of these specifications, and the presented estimates approximate the mid-point of the various point estimates.
} 
the pattern is reversed, with Black testers being steered toward less White neighborhoods to a much greater degree than their White counterparts.

A similar conclusion is reached when steering is evaluated based on the initial Black shares, with Blacks being steered away from neighborhoods with low Black shares and Whites being steered (heavily) away from majority Black neighborhoods. Indeed, the steering estimate for White testers starting in majority-Black neighborhoods is the largest of any of the racial steering estimates we report, finding that neighborhood White shares increase by about 3.5 percentage points in the full sample, and 7.8 points in the same-firstunit sample, for each additional unit shown.

The results for neighborhood home values, at least in the full sample, largely mirror these patterns of racial steering, with Whites involved in an audit initiated in low-White neighborhoods being steered toward more affluent neighborhoods, and Black testers in mostly-White (or low-Black) neighborhoods being steered toward neighborhoods with lower home values.

\section{Conclusion}

Despite decades of progress toward racial integration, American cities remain highly stratified by race, and residential segregation continues to shape the social, economic, and political well-being of the U.S. population. Empirical work has demonstrated that persistent racial gaps in socioeconomic resources, residential racial preferences that - while liberalizing - continue to favor same-race neighborhoods, and racially-homogenous social networks contribute to the persistence of segregation (see Krysan and Crowder 2018). Scholarship has also consistently argued that segregation is maintained via discriminatory practices of housing agents that block minority homeseekers from access to integrated and 
White neighborhoods (Massey and Denton 1993; Carr and Kutty 2008). Yet, a consistent set of experimental audit studies demonstrate that overall levels of overt housing discrimination have declined precipitously over the last several decades (Ross and Turner 2005; Turner et al. 2013; Pitingolo and Ross 2015). This contradiction could result from limits to the ability of audit tests to capture discrimination where it takes place (e.g., in mortgage lending, rather than in real estate), but it could also stem from failures of past work to fully capture the dynamics of racial steering, whereby real estate agents engage in practices that point White and minority homeseekers into different types of neighborhoods.

In this study, we sought to describe the dynamics of racial steering by attempting to answer two key questions: 1) Does steering characterize the housing searches for minority home seekers? 2) When in the search process does it occur, if at all? And 3) Under what conditions is it most likely to occur? We extended past work by conceptualizing steering as a dynamic process that unfolds as housing agents show home seekers potential homes, and explored some features of agents, homeseekers, and neighborhoods that set in motion a process of steering. To do so we used information on the homes shown or recommended to testers in over 2,600 housing audits conducted in by the U.S. Department of Housing and Urban Development that provide quasi-experimental data points for assessing our research questions. Our analytic approach leveraged the experimental quality of the audits to fit dynamic models, with audit fixed effects, that provide direct evidence on patterns of steering as the housing search develops.

Our results provide mixed evidence on the frequency of racial steering in U.S. housing markets. On the one hand, we confirmed prior work in finding no evidence of the differential steering of Hispanic or Asian testers, either in terms of neighborhood racial or socioeconomic composition (see Galster and Godfrey 2005; Ross and Turner 2005). In other words, our 
estimates did not indicate that real estate agents systematically show homes to Hispanic or Asian testers in ways that differ from their White counterparts.

On the other hand, we found consistent indications that black homeseekers are systematically steered away from White neighborhoods and toward Black ones. Specifically, our models indicate that for testers within the same audit, each additional home shown to a Black tester is located in a neighborhood that is about 1 percentage point less White and 0.6 percentage points more Black, than their White audit peers. While this may seem like a modest impact, representative data from the National Association of Realtors indicates that the typical homebuyer visits a median of 10 homes before a purchase is made (NAR 2018), implying that the impact of steering on racial differences in neighborhood context could be as large as 10 percentage points in White shares and 6 points in Black shares.

Our approach also allowed us to explore the conditions under which steering is most likely. In terms of homebuyers, our models suggest that steering is most common among Black women and those with children. Recent research has shown that black children are the most racially segregated age group in the U.S. (see Iceland et al. 2010; Jargowsky 2014; Owens 2016, 2017), which is often attributed to preferences for White parents to raise their children in neighborhoods where the schools tend to be Whiter. While the migratory behaviors of White parents (and their children) are likely a dominant explanation for the high segregation of Black children, the steering of Black mothers away from White neighborhoods is an important overlooked dimension. This finding underscores the importance of considering "intersecting" identities in understanding discriminatory behaviors (see Collins 1990; Crenshaw 1989; Harnois and Ifatunji 2011), with relevant research finding that Black women are regularly stereotyped as lacking the resources or ability to be self-sufficient (Timberlake and Estes 2007) and provoke images of family 
dysfunction (Kennelly 1999; Moss and Tilly 2001). This finding is also consistent with prior research demonstrating the discriminatory barriers that impact Black women in various institutional capacities, including the workplace (Ortiz and Roscigno 2009), consumer markets (Ayres and Siegelman 1995), and access to housing (Desmond 2012; Massey and Lundy 2001.

This work also demonstrates that steering is conditioned by features of housing units and neighborhoods where the home search begins. Specifically, our estimates indicate that Black steering away from white neighborhoods is most pronounced when the initial home is relatively high priced (i.e., has a listed value above the county median), and when that home is located in a mostly-White neighborhood. The implication of this, of course, is that while lower-resourced Black families may be priced out of White neighborhoods, betterresourced Black families may be steered away from them, which will contribute to the continued segregation of the Black middle class (Iceland and Wilkes 2006; Intrator, Tannen and Massey 2016; Pattillo 2013). While our estimates emphasize that the targets of steering are generally Black homebuyers, we do find evidence of the steering of White homebuyers when home searches begin in Black neighborhoods. Indeed, across all of our models and specifications, steering appears to be most pronounced for White homeseekers who start their searches in majority-Black neighborhoods.

From a theoretical standpoint, we outlined several possible explanations for why steering may function in real estate markets. While our analyses are not positioned to test specific hypotheses about the mechanics of steering, our models are suggestive that theories based solely of a "taste for discrimination" are incomplete. In particular, we find that the steering of Black homebuyers is about equally likely to occur when homeseekers search with White and minority agents, a result that strikes us as incompatible with a taste for 
discrimination argument. Instead, explanations-plausibly grounded in rational, profitseeking action-based on statistical discrimination or customer prejudice seem to have greater explanatory potential. Understanding the precise mechanisms through which steering operates is something that future research needs to explore.

Taken together, our analyses lead to several general implications: first, the steering of Black homeseekers, particularly women and those with children, is clearly evident, and will contribute to maintaining the high levels of segregation observed in American cities. This is especially so given our findings about the timing of steering early as opposed to late in the search process. Our findings suggest that Black homeseekers tend to be moved quickly out of the neighborhoods in which the search process began and into increasingly monoracial neighborhoods. This would suggest that Black homeseekers who attempt to make integrating moves may be thwarted, which could lead more strongly to persisting segregation than if steering occurred late in the search process.

However, the magnitude of the steering estimates are, for the most part, modest and should be interpreted cautiously. The main takeaway is that while steering likely contributes to the segregation of Black and White Americans, its role is likely to be relatively small and surely is not the only, or even dominant, explanation for understanding contemporary patterns of segregation. It is also crucial to emphasize that our estimates - like those of others that precede us - find no evidence of the steering of Hispanic or Asian homebuyers. Nevertheless, these results support policy proposals that would increase the costs of racial steering through governmental sanction or the additional training of real estate agents on the discriminatory impact of steering practices, even if done on the basis of perceived preferences of clients. 


\section{References}

Ayres, I. and Siegelman, P., 1995. "Race and gender discrimination in bargaining for a new car." American Economic Review, 304-21.

Becker, Gary S. 1971. The Economics of Discrimination. $2^{\text {nd }}$ ed. Chicago, IL: University of Chicago Press.

Besbris, Max, and Jacob William Faber. 2017. "Investigating the Relationship between Real Estate Agents, Segregation, and House Prices: Steering and Upselling in New York State." Sociological Forum 32:850-873.

Bruce, Neil C. 1977. "Real Estate Steering and the Fair Housing Act of 1968." Tulsa Law Journal 12:758-773.

Carr, J.H. and Kutty, N.K. eds., 2008. Segregation: The rising costs for America. Routledge. Collins, Patricia Hill. 1990. Black feminist thought. Boston: Unwin Hyman.

Crenshaw, K., 1989. "Demarginalizing the intersection of race and sex: A black feminist critique of antidiscrimination doctrine, feminist theory and antiracist politics." University of Chicago Legal Forum, p. 139-67.

Desmond, M., 2012. "Eviction and the reproduction of urban poverty." American Journal of Sociology, 118:88-133.

Galster, George and Erin Godfrey. 2005. "By Words and Deeds: Racial Steering by Real Estate Agents in the U.S. in 2000." Journal of the American Planning Association $71: 251-68$.

Galster, George. 1990. "Racial Steering by Real Estate Agents: Mechanisms and Motives." The Review of Black Political Economy 19:39-63. 
Gotham, Kevin Fox. 2002. "Beyond Invasion and Succession: School Segregation, Real Estate Blockbusting, and the Political Economy of Neighborhood Racial Transition." City 6 Community 1:83-111.

Hakken, Jon. 1979. Discrimination against Chicanos in the Dallas Rental Housing Market: An Experimental Extension of the Housing Market Practices Survey. Washington, DC.: U.S. Department of Housing and Urban Development.

Harnois, C.E. and Ifatunji, M., 2011. "Gendered measures, gendered models: toward an intersectional analysis of interpersonal racial discrimination." Ethnic and Racial Studies, 34:1006-28.

Heckman, James J., and Peter Siegelman. 1993. "The Urban Institute Audit Studies: Their Methods and Findings." Pp. 187-258 in Clear and Convincing Evidence: Measurement of Discrimination in America, edited by M. Fix and R.J. Struyk. Washington, DC: The Urban Institute Press.

Heckman, James J. 1998. "Detecting Discrimination." Journal of Economic Perspectives 12(2):101-116.

HUD (U.S. Department of Housing and Urban Development). 2019a. "Code of Federal Regulations, Part 100: Discriminatory Conduct under the Fair Housing Act." U.S. Government Publishing Office. Retrieved July $12, \quad 2019$ (https://www.govinfo.gov/content/pkg/CFR-2017-title24-vol1/xml/CFR-2017title24-vol1-part100.xml\#seqnum100.70). . 2019b. "Examples of Housing Discrimination." Retrieved July 17, 2019 (https://www.hud.gov/program offices/fair housing equal opp/examples housi ng discrimination). 
Iceland, J., Goyette, K. A., Nelson, K. A., \& Chan, C. 2010. "Racial and ethnic residential segregation and household structure: A research note." Social Science Research 39: $39-47$.

Iceland, John, and Gregory Sharp. 2013. "White Residential Segregation in U.S. Metropolitan Areas: Conceptual Issues, Patterns, and Trends from the U.S. Census, 1980 to 2010."

Iceland, J. and Wilkes, R., 2006. Does socioeconomic status matter? Race, class, and residential segregation. Social Problems, 53(2), pp.248-273.

Intrator, J., Tannen, J., \& Massey, D. S. (2016). Segregation by race and income in the United States 1970-2010. Social Science Research,60(1), 45-60. Population Research 6 Policy Review 32:663-686.

Jargowsky, Paul A. 2014. "Segregation, Neighborhoods, and Schools," in Annette Lareau and Kimberly Goyette, Choosing Homes, Choosing Schools. New York: Russell Sage.

Kennelly, I., 1999. “'That Single-Mother Element' How White Employers Typify Black Women." Gender \&S Society, 13:168-92.

Korver-Glenn, Elizabeth. 2018. "Compounding Inequalities: How Racial Stereotypes and Discrimination Accumulate across the Stages of Housing Exchange." American Sociological Review 83(4):627-56.

Krysan, Maria, and Kyle Crowder. 2017. Cycle of Segregation: Social Processes and Residential Stratification. New York: Russell Sage Foundation.

Logan, John, and Brian J. Stults. 2011. "The Persistence of Segregation in the Metropolis: New Findings from the 2010 Census." US2010 Project Report. Retrieved January 16, 2020 (https://s4.ad.brown.edu/Projects/Diversity/Data/Report/report2.pdf). 
Massey, Douglas, and Nancy Denton. 1993. American Apartheid: Segregation and the Making of the Underclass. Cambridge, MA: Harvard University Press.

Massey, Douglas S., and Mary J. Fischer. 2004. "The Social Ecology of Racial Discrimination." City \& Community 3:221-43.

Massey, D.S. and Lundy, G., 2001. "Use of Black English and racial discrimination in urban housing markets: New methods and findings." Urban Affairs Review, 36:452-69.

Moss, P. and Tilly, C., 2001. Stories employers tell: Race, skill, and hiring in America. New York, NY: Russell Sage Foundation.

National Research Council. 2004. Measuring Racial Discrimination. Washington, DC: The National Academies Press.

Oh, Sun Jung, and John Yinger. 2015. "What Have We Learned from Paired Testing in Housing Markets?" Cityscape: A Journal of Policy Development and Research 17:1560.

Ortiz, S.Y. and Roscigno, V.J., 2009. "Discrimination, women, and work: Processes and variations by race and class." The Sociological Quarterly, 50:336-59.

Owens, Ann. 2016. "Inequality in Children's Contexts: Income Segregation of Households with and without Children," American Sociological Review, 81: 549-74.

. 2017. "Racial Residential Segregation of School-Age Children and Adults: The Role of Schoolings as a Segregating Force." The Russell Sage Foundation Journal of the Social Sciences, 3: 63-80.

Pattillo, Mary. 2013. Black picket fences: Privilege and peril among the black middle class. Chicago, IL: University of Chicago Press.

Pearce, Diana. 1979. "Gatekeepers and Homeseekers: Institutional Patterns in Racial Steering." Social Problems 26:325-42. 
Phelps, Edmund S. 1972. "The Statistical Theory of Racism and Sexism." The American Economic Association 62(4):659-61.

Pitingolo, Rob and Stephen L. Ross. 2015. "Housing Discrimination among Available Housing Units in 2012: Do Paired-Testing Studies Underestimate Housing Discrimination?" Cityscape: A Journal of Policy Development and Research 17:6185.

Quillian, Lincoln. 2006. "New Approaches to Understanding Racial Prejudice and Discrimination." Annual Review of Sociology 32:299-328.

Ross, Stephen L., Margery Austin Turner. 2005. "Housing Discrimination in Metropolitan America: Explaining Changes between 1989 and 2000." Social Problems 52:152-80.

Rothstein, Richard. 2018. The Color of Law: A Forgotten History of How Our Government Segregated America. New York: Liveright Publishing Company.

Rugh, J.S. and Massey, D.S. 2014. "Segregation in post-civil rights America: Stalled integration or end of the segregated century?" Du Bois Review, 11: 205-32.

Schill, Michael H., and Samantha Friedman. 1999. "The Fair Housing Amendments Act of 1988: The First Decade." Cityscape: A Journal of Policy Development and Research $4(3): 57-78$.

Taylor, Keeanga-Yamahtta. 2019. Race for Profit: How Banks and the Real Estate Industry Undermined Black Homeownership. Chapel Hill, NC: The University of North Carolina Press.

Timberlake, J.M. and Estes, S.B., 2007. "Do racial and ethnic stereotypes depend on the sex of target group members? Evidence from a survey-based experiment." The Sociological Quarterly, 48:399-433. 
Timberlake, Jeffrey M., and John Iceland. 2007. "Change in Racial and Ethnic Residential Inequality in American Cities, 1970-2000." City $\&$ Community 6(4):335-365.

Turner, Margery, John Edwards, and Maris Mikelsons. 1991. "Incidence and Severity of Racial and Ethnic Steering." Pp. 21-49 in Housing Discrimination Study: Analyzing Racial and Ethnic Steering. Washington, DC: U.S. Department of Housing and Urban Development.

Turner, Margery Austin, Diane K. Levy, Doug Wissoker, Claudia L. Aranda, Rob Pitingolo, and Rob Santos. 2013. Housing Discrimination Against Racial and Ethnic Minorities 2012. Washington, DC: U.S. Department of Housing and Urban Development.

U.S. DOJ (U.S. Department of Justice). 2020. "Housing Cases Summary Page." Retrieved January 11, 2020 (https://www.justice.gov/crt/housing-cases-summary-page).

Vigdor, Jacob L., and Edward L. Glaeser. 2012. The End of the Segregated Century: Racial Separation in America's Neighborhoods, 1890-2012. New York: Manhattan Institute.

Wienk, Ronald E., Clifford E. Reid, John C. Simonson, and Frederick J. Eggers. 1979. Measuring Discrimination in American Housing Markets. The Housing Market Practices Survey. Washington, DC: U.S. Department of Housing and Urban Development

Yinger, John. 1995. Closed Doors, Opportunities Lost: The Continuing Costs of Housing Discrimination. New York: Russell Sage Foundation. 
Figure 1.Hypothetical Examples of Housing Searches
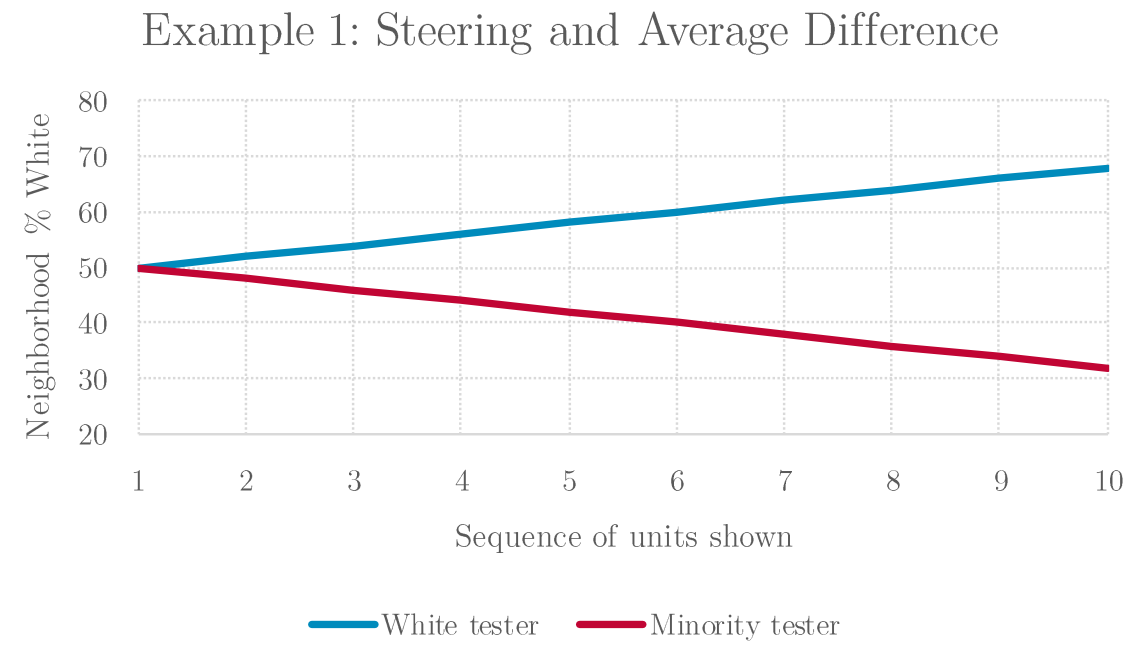

Example 2: Steering but no Average Difference

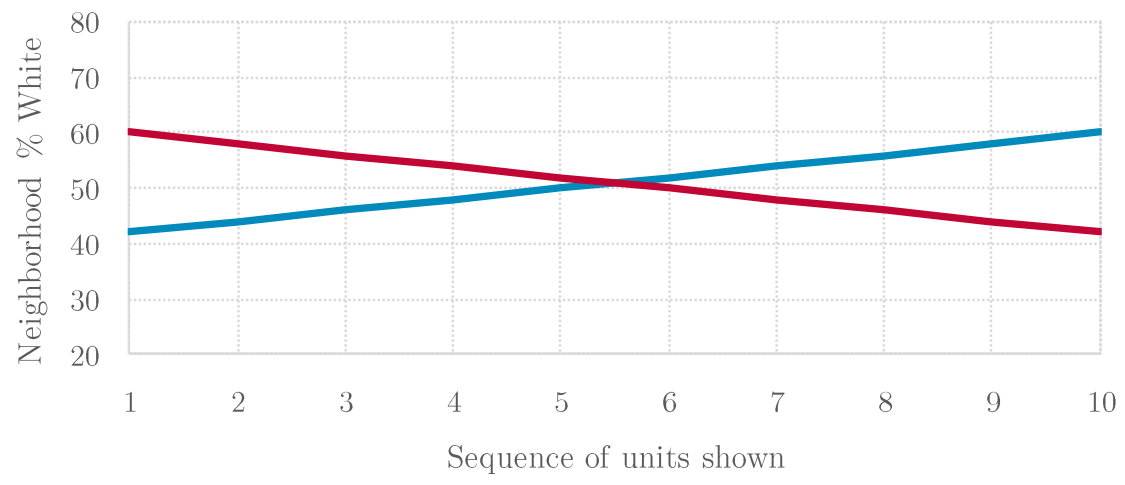

White tester $\longrightarrow$ Minority tester

Example 3: Average Difference but no Steering

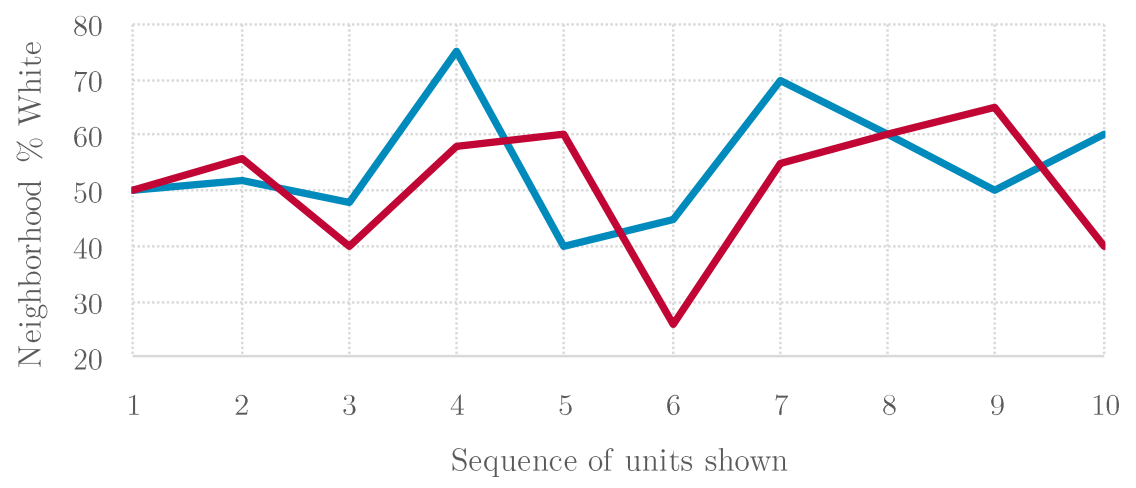

White tester $\longrightarrow$ Minority tester 
Figure 2: Racial Steering Curves for Black/White Audits
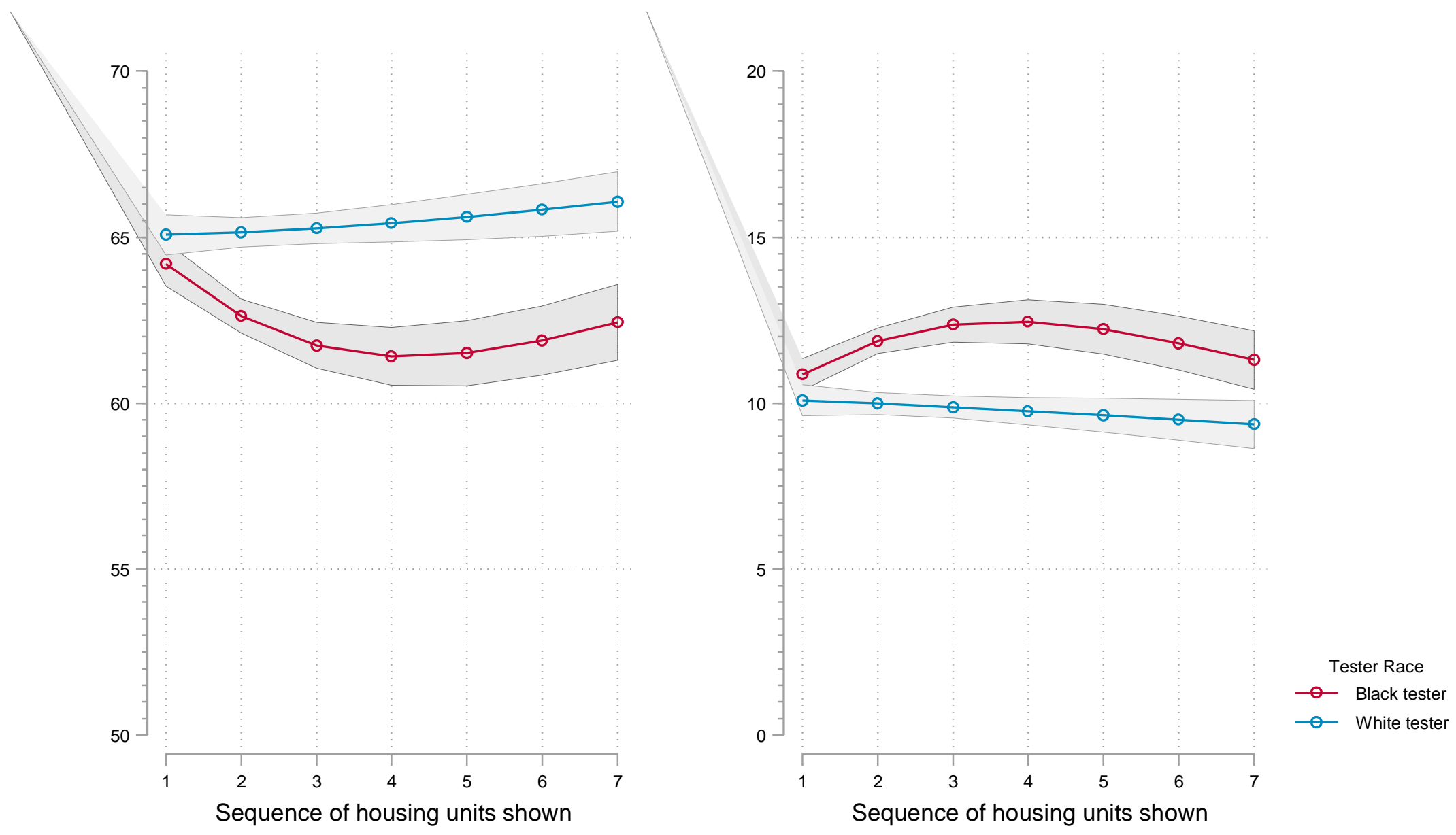

Notes: based on estimates shown in Table 2, which include controls for order in which testers were assigned to approach agent, time and day of visit, number of visits with agent, whether the tester had a college education, and whether the tester had prior auditing experience. 
Table 1: Characteristics of Unit Neighborhoods and Audits, 2012

\begin{tabular}{|c|c|c|c|c|c|c|c|c|c|c|c|c|c|c|c|}
\hline & \multicolumn{5}{|c|}{ Black-White Audits } & \multicolumn{5}{|c|}{ Hispanic-White Audits } & \multicolumn{5}{|c|}{ Asian-White Audits } \\
\hline & \multicolumn{2}{|c|}{ White tester } & \multicolumn{2}{|c|}{ Black tester } & \multirow{2}{*}{$\begin{array}{c}\mathrm{p}-\mathrm{val} \\
\left(\mu_{\mathrm{b}}=\mu_{\mathrm{w}}\right)\end{array}$} & \multicolumn{2}{|c|}{ White tester } & \multicolumn{2}{|c|}{ Hispanic tester } & \multirow{2}{*}{$\begin{array}{c}\text { p-val } \\
\left(\mu_{h}=\mu_{w}\right)\end{array}$} & \multicolumn{2}{|c|}{ White tester } & \multicolumn{2}{|c|}{ Asian tester } & \multirow{2}{*}{$\begin{array}{c}\text { p-val } \\
\left(\mu_{\mathrm{a}}=\mu_{\mathrm{w}}\right.\end{array}$} \\
\hline & Mean & $(\mathrm{SD})$ & Mean & $(\mathrm{SD})$ & & Mean & $(\mathrm{SD})$ & Mean & $(\mathrm{SD})$ & & Mean & $(\mathrm{SD})$ & Mean & $(\mathrm{SD})$ & \\
\hline \multicolumn{16}{|l|}{ Neighborhood characteristics } \\
\hline$\%$ non-Hispanic White & 64.61 & $(22.36)$ & 62.03 & $(23.33)$ & $.017 *$ & 61.06 & $(23.47)$ & 60.62 & $(23.78)$ & .700 & 61.99 & $(22.45)$ & 61.55 & $(22.19)$ & .679 \\
\hline$\%$ non-Hispanic Black & 9.71 & $(12.55)$ & 11.23 & $(15.38)$ & $.022 *$ & 8.55 & $(12.85)$ & 8.72 & $(12.91)$ & .784 & 8.41 & $(13.39)$ & 8.17 & $(12.07)$ & .692 \\
\hline$\%$ Hispanic & 16.52 & $(18.93)$ & 16.40 & $(18.33)$ & .891 & 20.48 & $(20.58)$ & 21.16 & $(21.16)$ & .508 & 18.64 & $(17.87)$ & 18.92 & $(18.27)$ & .747 \\
\hline$\%$ non-Hispanic asian & 6.69 & $(7.34)$ & 6.83 & $(8.22)$ & .702 & 7.41 & $(8.69)$ & 7.02 & $(8.43)$ & .358 & 8.26 & $(8.97)$ & 8.66 & $(9.36)$ & .362 \\
\hline$\%$ in poverty & 8.63 & $(8.23)$ & 8.68 & $(8.34)$ & .899 & 8.76 & $(7.63)$ & 9.22 & $(8.45)$ & .247 & 8.24 & $(7.68)$ & 8.24 & $(7.08)$ & .999 \\
\hline$\%$ with college degree + & 26.54 & $(10.43)$ & 25.83 & $(10.39)$ & .149 & 25.68 & $(10.48)$ & 25.10 & $(10.62)$ & .259 & 26.39 & $(10.64)$ & 26.09 & $(10.54)$ & .553 \\
\hline Median home value (in $\$ 1,000$ s) & 307.44 & $(179.27)$ & 304.42 & $(181.43)$ & .722 & 310.23 & $(178.55)$ & 304.26 & $(176.76)$ & .495 & 339.57 & $(196.60)$ & 334.84 & $(191.32)$ & .609 \\
\hline $\mathrm{N}$ of audits & \multicolumn{5}{|c|}{924} & \multicolumn{5}{|c|}{843} & \multicolumn{4}{|c|}{895} & \\
\hline
\end{tabular}


Table 2: Average Marginal Effects of Racial Steering for Black-White Audits

\begin{tabular}{|c|c|c|c|c|c|c|}
\hline \multirow[b]{3}{*}{ Neighborhood Outcomes } & \multicolumn{6}{|c|}{ Black-White audits } \\
\hline & \multicolumn{3}{|c|}{ All audits } & \multicolumn{3}{|c|}{ Same 1st-unit audits } \\
\hline & $\begin{array}{l}\text { Black } \\
\text { tester }\end{array}$ & $\begin{array}{l}\text { White } \\
\text { tester }\end{array}$ & $\begin{array}{c}\mathrm{p} \text {-val } \\
\left(\beta_{\mathrm{b}}=\beta_{\mathrm{w}}\right)\end{array}$ & $\begin{array}{l}\text { Black } \\
\text { tester } \\
\end{array}$ & $\begin{array}{l}\text { White } \\
\text { tester }\end{array}$ & $\begin{array}{c}\mathrm{p} \text {-val } \\
\left(\beta_{\mathrm{b}}=\beta_{\mathrm{w}}\right)\end{array}$ \\
\hline \multirow[t]{2}{*}{$\%$ White } & $-1.040 * * *$ & .138 & $.000 * * *$ & $-.950 *$ & .127 & $.012 *$ \\
\hline & $(.212)$ & $(.145)$ & & $(.375)$ & $(.300)$ & \\
\hline \multirow[t]{2}{*}{$\%$ Black } & $.670 * * *$ & -.111 & $.000 * * *$ & $.521 *$ & -.193 & $.009 * *$ \\
\hline & $(.163)$ & $(.113)$ & & $(.261)$ & $(.192)$ & \\
\hline \multirow[t]{2}{*}{$\%$ Hispanic } & .113 & .023 & .483 & .212 & -.097 & .128 \\
\hline & $(.119)$ & $(.082)$ & & $(.224)$ & $(.160)$ & \\
\hline \multirow[t]{2}{*}{$\%$ Asian } & $.245 * *$ & -.032 & $.009 * *$ & .200 & .211 & .958 \\
\hline & $(.083)$ & $(.068)$ & & $(.127)$ & $(.168)$ & \\
\hline \multirow[t]{2}{*}{$\%$ in poverty } & .092 & -.010 & .408 & -.130 & -.048 & .616 \\
\hline & $(.093)$ & $(.082)$ & & $(.169)$ & $(.145)$ & \\
\hline \multirow[t]{2}{*}{$\%$ college educated } & -.051 & -.062 & .937 & .245 & .364 & .592 \\
\hline & $(.113)$ & $(.089)$ & & $(.214)$ & $(.176)$ & \\
\hline \multirow[t]{2}{*}{ Median home value (in $\$ 1,000 \mathrm{~s}$ ) } & $-5.486 * * *$ & .094 & $.000 * * *$ & -.483 & 1.648 & .319 \\
\hline & $(1.038)$ & $(1.079)$ & & $(2.018)$ & $(1.871)$ & \\
\hline Audit FEs & & Yes & & & Yes & \\
\hline Controls & & Yes & & & Yes & \\
\hline Number of housing units & & 6,375 & & & 2,398 & \\
\hline Number of audits & & 924 & & & 416 & \\
\hline
\end{tabular}

Notes: ${ }^{*} \mathrm{p}<0.05 ;{ }^{*} \mathrm{p}<0.01 ;{ }^{* * *} \mathrm{p}<0.001$; models control for order in which testers were assigned to approach agent, time and day of the visit, number of visits with agent, whether the tester had a college education, and whether the test had prior auditing experience 
Table 3: Average Marginal Effects of Racial Steering for Hispanic-White Audits

\begin{tabular}{|c|c|c|c|c|c|c|}
\hline \multirow[b]{3}{*}{ Neighborhood Outcomes } & \multicolumn{6}{|c|}{ Hispanic-White audits } \\
\hline & \multicolumn{3}{|c|}{ All audits } & \multicolumn{3}{|c|}{ Same 1st-unit audits } \\
\hline & $\begin{array}{c}\text { Hispanic } \\
\text { tester }\end{array}$ & $\begin{array}{l}\text { White } \\
\text { tester }\end{array}$ & $\begin{array}{c}\mathrm{p}-\mathrm{val} \\
\left(\beta_{\mathrm{h}}=\beta_{\mathrm{w}}\right)\end{array}$ & $\begin{array}{l}\text { Black } \\
\text { tester }\end{array}$ & $\begin{array}{l}\text { White } \\
\text { tester }\end{array}$ & $\begin{array}{c}\mathrm{p}-\mathrm{val} \\
\left(\beta_{\mathrm{b}}=\beta_{\mathrm{w}}\right)\end{array}$ \\
\hline \multirow[t]{2}{*}{$\%$ white } & .143 & -.191 & .200 & -.230 & -.008 & .590 \\
\hline & $(.190)$ & $(.178)$ & & $(.394)$ & $(.337)$ & \\
\hline \multirow[t]{2}{*}{$\%$ black } & -.052 & .174 & .191 & .279 & .188 & .764 \\
\hline & $(.110)$ & $(.133)$ & & $(.245)$ & $(.224)$ & \\
\hline \multirow[t]{2}{*}{$\%$ Hispanic } & -.081 & .102 & .255 & -.136 & -.236 & .670 \\
\hline & $(.135)$ & $(.113)$ & & $(.261)$ & $(.236)$ & \\
\hline \multirow[t]{2}{*}{$\%$ Asian } & -.025 & .007 & .787 & .056 & .002 & .807 \\
\hline & $(.090)$ & $(.085)$ & & $(.197)$ & $(.173)$ & \\
\hline \multirow[t]{2}{*}{$\%$ in poverty } & -.099 & .073 & .193 & -.117 & -.217 & .621 \\
\hline & $(.111)$ & $(.092)$ & & $(.220)$ & $(.187)$ & \\
\hline \multirow[t]{2}{*}{$\%$ college educated } & .080 & -.073 & .327 & .029 & .246 & .387 \\
\hline & $(.128)$ & $(.108)$ & & $(.216)$ & $(.224)$ & \\
\hline \multirow[t]{2}{*}{ Median home value (in $\$ 1,000 \mathrm{~s}$ ) } & -.272 & -1.677 & .390 & -.976 & .869 & .492 \\
\hline & $(1.338)$ & $(1.123)$ & & $(2.658)$ & $(2.233)$ & \\
\hline Audit FEs & & Yes & & & Yes & \\
\hline Controls & & Yes & & & Yes & \\
\hline Number of housing units & & 5,481 & & & 2,094 & \\
\hline Number of audits & & 843 & & & 392 & \\
\hline
\end{tabular}

Notes: ${ }^{*} \mathrm{p}<0.05 ;{ }^{*} \mathrm{p}<0.01 ;{ }^{* * *} \mathrm{p}<0.001$; models control for order in which testers were assigned to approach agent, time and day of the visit, number of visits with agent, whether the tester had a college education, and whether the test had prior auditing experience 
Table 4: Average Marginal Effects of Racial Steering for Asian-White Audits

\begin{tabular}{|c|c|c|c|c|c|c|}
\hline \multirow[b]{3}{*}{ Neighborhood Outcomes } & \multicolumn{6}{|c|}{ Asian-White audits } \\
\hline & \multicolumn{3}{|c|}{ All audits } & \multicolumn{3}{|c|}{ Same 1st-unit audits } \\
\hline & $\begin{array}{l}\text { Asian } \\
\text { tester }\end{array}$ & $\begin{array}{l}\text { White } \\
\text { tester }\end{array}$ & $\begin{array}{c}\mathrm{p} \text {-val } \\
\left(\beta_{\mathrm{a}}=\beta_{\mathrm{w}}\right)\end{array}$ & $\begin{array}{l}\text { Asian } \\
\text { tester }\end{array}$ & $\begin{array}{l}\text { White } \\
\text { tester }\end{array}$ & $\begin{array}{c}\mathrm{p}-\mathrm{val} \\
\left(\beta_{\mathrm{b}}=\beta_{\mathrm{w}}\right)\end{array}$ \\
\hline \multirow[t]{2}{*}{$\%$ white } & -.105 & -.136 & .896 & .018 & -.241 & .528 \\
\hline & $(.184)$ & $(.185)$ & & $(.375)$ & $(.392)$ & \\
\hline \multirow[t]{2}{*}{$\%$ black } & .066 & -.017 & .544 & -.156 & -.096 & .809 \\
\hline & $(.111)$ & $(.102)$ & & $(.260)$ & $(.211)$ & \\
\hline \multirow[t]{2}{*}{$\%$ Hispanic } & -.163 & .112 & .121 & -.230 & .215 & .152 \\
\hline & $(.111)$ & $(.138)$ & & $(.226)$ & $(.283)$ & \\
\hline \multirow[t]{2}{*}{$\%$ Asian } & $.183 *$ & .034 & .182 & $.346 *$ & .111 & .241 \\
\hline & $(.081)$ & $(.089)$ & & $(.146)$ & $(.193)$ & \\
\hline \multirow[t]{2}{*}{$\%$ in poverty } & -.140 & -.054 & .522 & -.193 & -.003 & .314 \\
\hline & $(.103)$ & $(.097)$ & & $(.184)$ & $(.172)$ & \\
\hline \multirow[t]{2}{*}{$\%$ college educated } & .177 & .225 & .786 & .270 & .389 & .675 \\
\hline & $(.112)$ & $(.137)$ & & $(.251)$ & $(.244)$ & \\
\hline \multirow[t]{2}{*}{ Median home value (in $\$ 1,000 \mathrm{~s}$ ) } & -.062 & .571 & .703 & -1.887 & -.492 & .651 \\
\hline & $(1.243)$ & $(1.259)$ & & $(2.576)$ & $(2.699)$ & \\
\hline Audit FEs & & Yes & & & Yes & \\
\hline Controls & & Yes & & & Yes & \\
\hline Number of housing units & & 5,886 & & & 2,264 & \\
\hline Number of audits & & 895 & & & 438 & \\
\hline
\end{tabular}

Notes: ${ }^{*} \mathrm{p}<0.05 ;{ }^{*} \mathrm{p}<0.01 ;{ }^{* * *} \mathrm{p}<0.001 ;$ models control for order in which testers were assigned to approach agent, time and day of the visit, number of visits with agent, whether the tester had a college education, and whether the test had prior auditing experience 
Table 5: Average Marginal Effects of Racial Steering in Black-White Audits, by Agent and Tester Characteristics

\begin{tabular}{|c|c|c|c|c|c|c|c|c|c|c|c|c|}
\hline & \multicolumn{12}{|c|}{ Black-White audits } \\
\hline & \multicolumn{6}{|c|}{ All audits } & \multicolumn{6}{|c|}{ Same 1st-unit audits } \\
\hline & \multicolumn{3}{|c|}{ N'hood \% White } & \multicolumn{3}{|c|}{ N'hood median home value } & \multicolumn{3}{|c|}{ N'hood \% White } & \multicolumn{3}{|c|}{ N'hood median home value } \\
\hline & $\begin{array}{l}\text { Black } \\
\text { tester }\end{array}$ & $\begin{array}{l}\text { White } \\
\text { tester }\end{array}$ & $\begin{array}{c}\mathrm{p}-\mathrm{val} \\
\left(\beta_{\mathrm{b}}=\beta_{\mathrm{w}}\right)\end{array}$ & $\begin{array}{l}\text { Black } \\
\text { tester }\end{array}$ & $\begin{array}{l}\text { White } \\
\text { tester }\end{array}$ & $\begin{array}{c}\mathrm{p}-\mathrm{val} \\
\left(\beta_{\mathrm{b}}=\beta_{\mathrm{w}}\right)\end{array}$ & $\begin{array}{l}\text { Black } \\
\text { tester }\end{array}$ & $\begin{array}{l}\text { White } \\
\text { tester }\end{array}$ & $\begin{array}{c}\mathrm{p}-\mathrm{val} \\
\left(\beta_{\mathrm{b}}=\beta_{\mathrm{w}}\right)\end{array}$ & $\begin{array}{l}\text { Black } \\
\text { tester }\end{array}$ & $\begin{array}{l}\text { White } \\
\text { tester }\end{array}$ & $\begin{array}{c}\mathrm{p}-\mathrm{val} \\
\left(\beta_{\mathrm{b}}=\beta_{\mathrm{w}}\right)\end{array}$ \\
\hline \multicolumn{13}{|l|}{ Agent Race } \\
\hline Minority agent & $\begin{array}{l}-1.308 * \\
(.555)\end{array}$ & $\begin{array}{r}.030 \\
(.363)\end{array}$ & $.035 *$ & $\begin{array}{l}-3.769 \\
(2.329)\end{array}$ & $\begin{array}{l}4.155+ \\
(2.296)\end{array}$ & $.010 *$ & $\begin{array}{r}-1.309 \\
(.920)\end{array}$ & $\begin{array}{r}.082 \\
(.410)\end{array}$ & .223 & $\begin{array}{l}-2.425 \\
(2.956)\end{array}$ & $\begin{array}{r}2.623 \\
(4.129)\end{array}$ & .243 \\
\hline White agent & $\begin{array}{l}-.947^{* * *} \\
(.239)\end{array}$ & $\begin{array}{r}.199 \\
(.165)\end{array}$ & $.000 * * *$ & $\begin{array}{l}-5.422^{* * *} \\
(1.257)\end{array}$ & $\begin{array}{r}-.322 \\
(1.265)\end{array}$ & $.003 * * *$ & $\begin{array}{l}-1.068 * \\
(.426)\end{array}$ & $\begin{array}{r}.308 \\
(.336)\end{array}$ & $.005 * *$ & $\begin{array}{r}.351 \\
(1.257)\end{array}$ & $\begin{array}{r}2.054 \\
(2.224)\end{array}$ & .519 \\
\hline \multicolumn{13}{|l|}{ Tester Gender } \\
\hline Female tester & $\begin{array}{l}-1.374^{* * *} \\
(.331)\end{array}$ & $\begin{array}{l}-.023 \\
(.201)\end{array}$ & $.000 * * *$ & $\begin{array}{l}-6.705^{* * *} \\
(1.581)\end{array}$ & $\begin{array}{r}-.241 \\
(1.335)\end{array}$ & $.000 * * *$ & $\begin{array}{l}-1.408 * \\
(.596)\end{array}$ & $\begin{array}{r}.389 \\
(.450)\end{array}$ & $.009 * *$ & $\begin{array}{r}.065 \\
(3.002)\end{array}$ & $\begin{array}{r}4.387 \\
(2.875)\end{array}$ & .174 \\
\hline Male tester & $\begin{array}{l}-.359 \\
(.351)\end{array}$ & $\begin{array}{r}.269 \\
(.195)\end{array}$ & .108 & $\begin{array}{l}-2.535 \\
(1.969)\end{array}$ & $\begin{array}{r}.336 \\
(1.720)\end{array}$ & .281 & $\begin{array}{l}-.440 \\
(.422)\end{array}$ & $\begin{array}{l}-.186 \\
(.406)\end{array}$ & .583 & $\begin{array}{l}-1.088 \\
(2.564)\end{array}$ & $\begin{array}{l}-1.158 \\
(2.401)\end{array}$ & .980 \\
\hline \multicolumn{13}{|l|}{ Tester Assigned Parent Status } \\
\hline Does not have children & $\begin{array}{l}-1.081 * \\
(.458)\end{array}$ & $\begin{array}{l}-.269 \\
(.224)\end{array}$ & .092 & $\begin{array}{l}-4.445 \\
(2.547)\end{array}$ & $\begin{array}{r}-.430 \\
(2.403)\end{array}$ & .222 & $\begin{array}{l}-1.452 * \\
(.715)\end{array}$ & $\begin{array}{l}-.943 \\
(.694)\end{array}$ & .561 & $\begin{array}{l}-2.105 \\
(4.331)\end{array}$ & $\begin{array}{l}-2.322 \\
(3.583)\end{array}$ & .956 \\
\hline Has children & $\begin{array}{l}-1.021^{* * *} \\
(.266)\end{array}$ & $\begin{array}{c}.336 \\
(.181)\end{array}$ & $.000^{* * *}$ & $\begin{array}{l}-4.786^{* * *} \\
(1.154)\end{array}$ & $\begin{array}{r}.272 \\
(1.040)\end{array}$ & $.000 * * *$ & $\begin{array}{l}-.762+ \\
(.462)\end{array}$ & $\begin{array}{l}.647+ \\
(.356)\end{array}$ & $.009 * *$ & $\begin{array}{r}.239 \\
(2.214)\end{array}$ & $\begin{array}{r}3.680 \\
(2.312)\end{array}$ & .173 \\
\hline Audit FEs & & Yes & & & Yes & & & Yes & & & Yes & \\
\hline Controls & & Yes & & & Yes & & & Yes & & & Yes & \\
\hline Number of housing units & & 6,375 & & & 6,375 & & & 2,398 & & & 2,398 & \\
\hline Number of audits & & 924 & & & 924 & & & 416 & & & 416 & \\
\hline
\end{tabular}

Notes: $+\mathrm{p}<0.10 ;^{*} \mathrm{p}<0.05 ;^{* *} \mathrm{p}<0.01 ;^{* * *} \mathrm{p}<0.001 ;$ models control for order in which testers were assigned to approach agent, time and day of the visit, number of visits with agent, whether the tester had a college education, and whether the tester had prior auditing experience 
Table 6: Average Marginal Effects of Racial Steering in Black-White Audits, by Unit Characteristic

\begin{tabular}{|c|c|c|c|c|c|c|c|c|c|c|c|c|}
\hline & \multicolumn{12}{|c|}{ Black-White audits } \\
\hline & \multicolumn{6}{|c|}{ All audits } & \multicolumn{6}{|c|}{ Same 1st-unit audits } \\
\hline & \multicolumn{3}{|c|}{ N'hood \% White } & \multicolumn{3}{|c|}{ N'hood median home value } & \multicolumn{3}{|c|}{ N'hood \% White } & \multicolumn{3}{|c|}{ N'hood median home value } \\
\hline & $\begin{array}{l}\text { Black } \\
\text { tester }\end{array}$ & $\begin{array}{l}\text { White } \\
\text { tester }\end{array}$ & $\begin{array}{c}\mathrm{p} \text {-val } \\
\left(\beta_{\mathrm{b}}=\beta_{\mathrm{w}}\right)\end{array}$ & $\begin{array}{l}\text { Black } \\
\text { tester }\end{array}$ & $\begin{array}{l}\text { White } \\
\text { tester }\end{array}$ & $\begin{array}{c}\mathrm{p} \text {-val } \\
\left(\beta_{\mathrm{b}}=\beta_{\mathrm{w}}\right)\end{array}$ & $\begin{array}{l}\text { Black } \\
\text { tester }\end{array}$ & $\begin{array}{l}\text { White } \\
\text { tester }\end{array}$ & $\begin{array}{c}\mathrm{p}-\mathrm{val} \\
\left(\beta_{\mathrm{b}}=\beta_{\mathrm{w}}\right)\end{array}$ & $\begin{array}{l}\text { Black } \\
\text { tester }\end{array}$ & $\begin{array}{l}\text { White } \\
\text { tester }\end{array}$ & $\begin{array}{c}\mathrm{p} \text {-val } \\
\left(\beta_{\mathrm{b}}=\beta_{\mathrm{w}}\right)\end{array}$ \\
\hline \multicolumn{13}{|l|}{ Advertised home price } \\
\hline Below county median home value & $\begin{array}{l}-.319 \\
(.406)\end{array}$ & $\begin{array}{r}.119 \\
(.282)\end{array}$ & .355 & $\begin{array}{c}-1.236 \\
(1.891)\end{array}$ & $\begin{array}{r}-.564 \\
(1.839)\end{array}$ & .768 & $\begin{array}{l}-.761 \\
(.682)\end{array}$ & $\begin{array}{r}.152 \\
(.565)\end{array}$ & .272 & $\begin{array}{r}-.168 \\
(3.032)\end{array}$ & $\begin{array}{r}1.480 \\
(3.209)\end{array}$ & .576 \\
\hline Above county median home value & $\begin{array}{l}-1.302^{* * *} \\
(.277)\end{array}$ & $\begin{array}{r}.213 \\
(.176)\end{array}$ & $.000 * * *$ & $\begin{array}{l}-5.615^{* * *} \\
(1.518)\end{array}$ & $\begin{array}{r}.304 \\
(1.414)\end{array}$ & $.003 * *$ & $\begin{array}{l}-1.073^{* *} \\
(.411)\end{array}$ & $\begin{array}{r}.085 \\
(.344)\end{array}$ & $.008 * *$ & $\begin{array}{r}-.403 \\
(2.769)\end{array}$ & $\begin{array}{r}1.568 \\
(2.383)\end{array}$ & .494 \\
\hline \multicolumn{13}{|l|}{ Neighborhood $\%$ white of first unit } \\
\hline Low $\%$ white $(0-50 \%)$ & $\begin{array}{l}.974 * \\
(.488)\end{array}$ & $\begin{array}{l}2.139 \text { *** } \\
(.438)\end{array}$ & $.005 * *$ & $\begin{array}{r}.438 \\
(2.275)\end{array}$ & $\begin{array}{r}4.936 * \\
(2.339)\end{array}$ & $.038 *$ & $\begin{array}{l}1.748 * * \\
(.631)\end{array}$ & $\begin{array}{l}2.806^{* * *} \\
(.722)\end{array}$ & $.073+$ & $\begin{array}{r}.215 \\
(2.927)\end{array}$ & $\begin{array}{r}5.114 \\
(3.330)\end{array}$ & $.060+$ \\
\hline Mid \% white $(50-75 \%)$ & $\begin{array}{l}-.679 \\
(.447)\end{array}$ & $\begin{array}{r}.156 \\
(.230)\end{array}$ & .062 & $\begin{array}{c}-2.393 \\
(2.697)\end{array}$ & $\begin{array}{r}1.369 \\
(1.167)\end{array}$ & .345 & $\begin{array}{l}-2.389 * * \\
(.727)\end{array}$ & $\begin{array}{l}-.333 \\
(.516)\end{array}$ & $.001 * *$ & $\begin{array}{r}.326 \\
(2.740)\end{array}$ & $\begin{array}{r}5.400 * \\
(2.726)\end{array}$ & $.033 *$ \\
\hline High \% white $(75-100 \%)$ & $\begin{array}{c}-1.381^{* * *} \\
(.255)\end{array}$ & $\begin{array}{l}-.447 * \\
(.187)\end{array}$ & $.001 * *$ & $\begin{array}{l}-6.501^{* * *} \\
(1.524)\end{array}$ & $\begin{array}{r}-.991 \\
(1.382)\end{array}$ & $.000 * * *$ & $\begin{array}{l}-1.557^{* * *} \\
(.357)\end{array}$ & $\begin{array}{l}-.686 * \\
(.298)\end{array}$ & $.015 *$ & $\begin{array}{l}-1.020 \\
(3.513)\end{array}$ & $\begin{array}{c}-2.498 \\
(3.171)\end{array}$ & .610 \\
\hline \multicolumn{13}{|l|}{ Neighborhood \% black of first unit } \\
\hline Low $\%$ black $(0-5 \%)$ & $\begin{array}{l}-1.148 * * * \\
(.278)\end{array}$ & $\begin{array}{l}-.490 * \\
(.222)\end{array}$ & $.038 *$ & $\begin{array}{l}-5.223^{* *} \\
(1.950)\end{array}$ & $\begin{array}{c}-1.637 \\
(1.962)\end{array}$ & .054 & $\begin{array}{l}-1.743^{* * *} \\
(.472)\end{array}$ & $\begin{array}{l}-.797 * \\
(.260)\end{array}$ & $.049 *$ & $\begin{array}{c}-1.881 \\
(3.099)\end{array}$ & $\begin{array}{r}-1.986 \\
(2.915)\end{array}$ & .969 \\
\hline Mid \% black $(5-50 \%)$ & $\begin{array}{l}-.836 \text { ** } \\
(.292)\end{array}$ & $\begin{array}{r}.147 \\
(.191)\end{array}$ & $.001 * *$ & $\begin{array}{l}-4.298 * * \\
(1.263)\end{array}$ & $\begin{array}{r}2.639 * \\
(1.036)\end{array}$ & $.000 * * *$ & $\begin{array}{l}-.625 * * \\
(.506)\end{array}$ & $\begin{array}{r}.495 \\
(.453)\end{array}$ & $.030 *$ & $\begin{array}{r}-.043 \\
(2.025)\end{array}$ & $\begin{array}{c}5.220 * \\
(2.169)\end{array}$ & $.008 * *$ \\
\hline High \% black (50-100\%) & $\begin{array}{r}1.388 \\
(1.069)\end{array}$ & $\begin{array}{l}3.521^{* * *} \\
(.827)\end{array}$ & $.008 * *$ & $\begin{array}{r}-.706 \\
(4.486)\end{array}$ & $\begin{array}{r}5.611 \\
(5.088)\end{array}$ & .058 & $\begin{array}{l}3.473^{\text {*** }} \\
(1.300)\end{array}$ & $\begin{array}{l}7.788^{* * *} \\
(1.779)\end{array}$ & $.021 *$ & $\begin{array}{r}8.930 \\
(6.125)\end{array}$ & $\begin{array}{l}19.308 * \\
(8.355)\end{array}$ & $.016 *$ \\
\hline Audit FEs & & Yes & & & Yes & & & Yes & & & Yes & \\
\hline Controls & & Yes & & & Yes & & & Yes & & & Yes & \\
\hline Number of housing units & & 6,375 & & & 6,375 & & & 2,398 & & & 2,398 & \\
\hline Number of audits & & 924 & & & 924 & & & 416 & & & 416 & \\
\hline
\end{tabular}

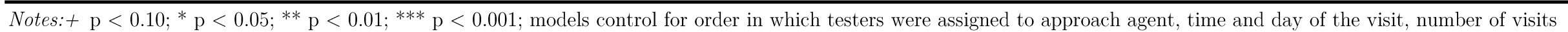
with agent, whether the tester had a college education, and whether the tester had prior auditing experience 


\section{Appendix Table A1: Average Marginal Effects of Racial Steering for Tract-Level} Characteristics

\begin{tabular}{|c|c|c|c|c|c|c|}
\hline \multirow[b]{3}{*}{ Neighborhood Outcomes } & \multicolumn{6}{|c|}{ Black-White audits } \\
\hline & \multicolumn{3}{|c|}{ All audits } & \multicolumn{3}{|c|}{ Same 1st-unit audits } \\
\hline & $\begin{array}{l}\text { Black } \\
\text { tester }\end{array}$ & $\begin{array}{l}\text { White } \\
\text { tester }\end{array}$ & $\begin{array}{c}\mathrm{p}-\mathrm{val} \\
\left(\beta_{\mathrm{b}}=\beta_{\mathrm{w}}\right)\end{array}$ & $\begin{array}{l}\text { Black } \\
\text { tester }\end{array}$ & $\begin{array}{l}\text { White } \\
\text { tester }\end{array}$ & $\begin{array}{c}\mathrm{p} \text {-val } \\
\left(\beta_{\mathrm{b}}=\beta_{\mathrm{w}}\right)\end{array}$ \\
\hline \multirow[t]{2}{*}{$\%$ White } & $-.931 * * *$ & .350 & $.000 * * *$ & $-1.081 * *$ & .125 & $.003 * *$ \\
\hline & $(.215)$ & $(.143)$ & & $(.394)$ & $(.278)$ & \\
\hline \multirow[t]{2}{*}{$\%$ Black } & $.688 * * *$ & -.082 & $.000 * * *$ & $.689 *$ & -.147 & $.003 * *$ \\
\hline & $(.156)$ & $(.150)$ & & $(.267)$ & $(.179)$ & \\
\hline \multirow[t]{2}{*}{$\%$ Hispanic } & .006 & .053 & .765 & -.038 & -.183 & .490 \\
\hline & $(.130)$ & $(.089)$ & & $(.247)$ & $(.152)$ & \\
\hline \multirow[t]{2}{*}{$\%$ Asian } & $.230 * *$ & .012 & $.016 *$ & $.406 * *$ & .235 & .361 \\
\hline & $(.077)$ & $(.062)$ & & $(.124)$ & $(.159)$ & \\
\hline \multirow[t]{2}{*}{$\%$ in poverty } & .058 & .056 & .983 & .132 & .020 & .407 \\
\hline & $(.076)$ & $(.066)$ & & $(.133)$ & $(.110)$ & \\
\hline \multirow[t]{2}{*}{$\%$ college educated } & .022 & .026 & .967 & .185 & $.377^{* *}$ & .261 \\
\hline & $(.088)$ & $(.069)$ & & $(.152)$ & $(.131)$ & \\
\hline \multirow{2}{*}{ Median home value (in $\$ 1,000 \mathrm{~s}$ ) } & $-5.297 * * *$ & -.255 & $.000 * * *$ & .150 & 1.766 & .421 \\
\hline & $(1.002)$ & $(1.127)$ & & $(1.718)$ & $(1.790)$ & \\
\hline Audit FEs & & Yes & & & Yes & \\
\hline Controls & & Yes & & & Yes & \\
\hline Number of housing units & & 6,375 & & & 2,398 & \\
\hline Number of audits & & 924 & & & 416 & \\
\hline
\end{tabular}

Notes: ${ }^{*} \mathrm{p}<0.05 ;{ }^{* *} \mathrm{p}<0.01 ;{ }^{* * *} \mathrm{p}<0.001 ;$ models control for order in which testers were assigned to approach agent, time and day of the visit, number of visits with agent, whether the tester had a college education, and whether the test had prior auditing experience 
Appendix Table A2: Descriptive statistics for tester characteristics included in analysis

\begin{tabular}{lcccc}
\hline & $\begin{array}{c}\text { White } \\
\text { testers }\end{array}$ & $\begin{array}{c}\text { Black } \\
\text { testers }\end{array}$ & $\begin{array}{c}\text { Hispanic } \\
\text { testers }\end{array}$ & $\begin{array}{c}\text { Asian } \\
\text { testers }\end{array}$ \\
\hline & & & & \\
College educated & .72 & .59 & .46 & .69 \\
Prior auditing experience & .24 & .26 & .24 & .13 \\
First visit with agent & .51 & .47 & .48 & .50 \\
Multiple visits with agent & .19 & .16 & .18 & .12 \\
Met with agent in morninধ & .44 & .44 & .42 & .41 \\
Day of visit & & & & \\
Monday & .12 & .11 & .10 & .10 \\
Tuesday & .11 & .12 & .11 & .10 \\
Wednesday & .15 & .14 & .15 & .16 \\
Thursday & .21 & .18 & .18 & .19 \\
Friday & .22 & .25 & .22 & .22 \\
Saturday & .13 & .14 & .16 & .15 \\
Sunday & .05 & .05 & .07 & .07 \\
\hline
\end{tabular}

